\title{
A STUDY TO DETERMINE THE EFFECTS OF INTRATHECAL FENTANYL COMBINED WITH 0.5\% BUPIVACAINE (HYPERBARIC) FOR SUBARACHNOID BLOCK ON THE DURATION AND QUALITY OF POST-OPERATIVE ANALGESIA
}

\author{
Moses Charles Dsouza ${ }^{1}$, Rahul Fernandez², Sumithra Selvam ${ }^{3}$
}

1 Professor, Department of Anaesthesiology and Critical Care, St. John's Medical College Hospital, Bangalore, Karnataka, India. ${ }^{2}$ Senior Resident, Department of Anaesthesiology and Critical Care, St. John's Medical College Hospital, Bangalore, Karnataka, India. ${ }^{3}$ Senior Resident, Division of Biostatistics, St. John's Medical College Hospital, Bangalore, Karnataka, India.

\section{ABSTRACT}

\section{BACKGROUND}

Spinal anaesthesia with hyperbaric Bupivacaine Hydrochloride has been popular for surgical procedures. The need to intensify and increase duration of sensory blockade without affecting motor blockade has led to the addition of fentanyl, thus prolonging the duration of post-operative analgesia. Aim of this study is to assess the duration and quality of post-operative pain relief when Hyperbaric Bupivacaine Hydrochloride is combined with fentanyl for sub-arachnoid block and also to study the prolongation of motor and sensory blockade.

\section{MATERIALS AND METHODS}

75 patients were randomly allocated into the following three groups Group A received SAB with 2.5 ml of $0.5 \%$ Bupivacaine Hydrochloride (Hyperbaric) Group B received SAB with addition of $10 \mu \mathrm{g}$ fentanyl to $2.5 \mathrm{ml}$ of $0.5 \%$ Bupivacaine Hydrochloride (Hyperbaric). Group C received SAB with addition of $25 \mu \mathrm{g}$ fentanyl to $2.5 \mathrm{ml}$ of $0.5 \%$ Bupivacaine Hydrochloride (Hyperbaric).

\section{RESULTS}

Mean duration of analgesia was increased with addition of fentanyl with $0.5 \%$ hyperbaric Bupivacaine intrathecally. Mean duration of analgesia was statistically highly significant in the fentanyl groups. The total dose of analgesics given in the postoperative period was highest in group A which was statistically significant. Times for two segment regression of sensory level were prolonged in group B and group C thus increasing the duration of sensory analgesia. Time to full motor recovery was not delayed in any of the three groups. The haemodynamic changes were similar in all the three groups with minimal changes in pulse rate and systolic blood pressure.

\section{CONCLUSION}

The addition of intrathecal fentanyl to the local anaesthetic injected intrathecally in subarachnoid block prolonged sensory analgesia obtained by the block without hampering recovery from motor block or causing untoward haemodynamic disturbances. Dose of $10 \mu \mathrm{g}$ fentanyl provided all these benefits which were accentuated by increasing the dose to $25 \mu \mathrm{g}$. Hence a dose of $10 \mu \mathrm{g}$ to $25 \mu \mathrm{g}$ as deemed fit is useful for this purpose.

\section{KEY WORDS}

Bupivacaine, Fentanyl, Intrathecal, Postoperative Analgesia.

HOW TO CITE THIS ARTICLE: Dsouza MC, Fernandez R, Selvam S. A study to determine the effects of intrathecal fentanyl combined with $0.5 \%$ bupivacaine (hyperbaric) for subarachnoid block on the duration and quality of post-operative analgesia. J. Evolution Med. Dent. Sci. 2018;7(51):5411-5415, DOI: 10.14260/jemds/2018/1198

\begin{tabular}{|c|c|}
\hline $\begin{array}{l}\text { BACKGROUND } \\
\text { Spinal anaesthesia is advantageous as it uses a small dose of } \\
\text { the anaesthetic, is simple to perform and offers a rapid onset } \\
\text { of action, reliable surgical analgesia and good muscle } \\
\text { relaxation. These advantages are sometimes offset by a } \\
\text { relatively short duration of action and complaints of post- } \\
\text { operative pain when it wears off. } \\
\text { Due to lack of step-down units where nurses can look } \\
\text { after epidural infusions and lack of equipment for PCA }\end{array}$ & $\begin{array}{l}\text { (Patient Controlled Analgesia), patients often have } \\
\text { breakthrough pain post-operatively. If we can provide } \\
\text { postoperative analgesia in a simple and inexpensive manner, } \\
\text { it may go a long way in alleviation of pain and suffering. } \\
\text { Spinal anaesthesia with hyperbaric Bupivacaine } \\
\text { Hydrochloride is popular for longer procedures due to its } \\
\text { prolonged duration. But there is a need to intensify and } \\
\text { increase duration of sensory blockade without increasing the } \\
\text { intensity and duration of motor blockade, and thus prolong }\end{array}$ \\
\hline $\begin{array}{l}\text { 'Financial or Other Competing Interest': None. } \\
\text { Submission 23-11-2018, Peer Review 05-12-2018, } \\
\text { Acceptance 07-12-2018, Published 17-12-2018. } \\
\text { Corresponding Author: } \\
\text { Dr. Rahul Fernandez, } \\
\text { Senior Resident, } \\
\text { Department of Anaesthesiology and Critical Care, }\end{array}$ & $\begin{array}{l}\text { the duration of post-operative analgesia. } 1 \text { The addition of } \\
\text { fentanyl has been suggested as a method to accomplish these } \\
\text { goals. } 2 \text { This study is designed to quantitatively examine the } \\
\text { effects of adding fentanyl to Hyperbaric Bupivacaine } \\
\text { Hydrochloride spinal anaesthesia on duration and recovery } \\
\text { of sensory and motor block. }\end{array}$ \\
\hline
\end{tabular}

St. John's Medical College Hospital,

Sarjapur Road, Bangalore,

Karnataka, India.

E-mail: fernandezrahul06@gmail.com

DOI: $10.14260 /$ jemds/2018/1198

\section{MATERIALS AND METHODS}

This randomized controlled trial study was conducted in tertiary care teaching Hospital after ethical committee approval. After written informed consent from all the patients, 75 patients belonging to "American Society of 
Anesthesiology" (ASA) GRADE I \& II Physical Status aged between 20 to 60 years, scheduled for elective low limb surgeries under spinal anesthesia were included in the study. Exclusion criteria were contraindications for Sub-arachnoid block.

Pre-anesthetic examination included general examination, systemic examination of cardiovascular, respiratory, CNS systems and examination of the spine for any disease or deformity.

Routine investigations were carried out before taking up the patient for surgery. Patient's height (In $\mathrm{cms}$ ) and weight (In kgs.) was also recorded. Premedication was standardized with Tab. Ranitidine $150 \mathrm{mg}$ PO oral the night before surgery and 2 hours before surgery, and Tab. diazepam $0.2 \mathrm{mg} / \mathrm{kg} P O$ on night before surgery. All patients were kept nil per orally from midnight. All patients were instructed about the visual analogue scale for pain.

0 - no pain and 10 - worst ever pain. Visual analogue scale was made by us using 10 beads on a string and shown to the patient during the preanesthetic evaluation. The first bead (White) of this string was explained as "no pain" and last bead (Red) as the "maximum pain". The intensity of the pain gradually increases from first bead to the tenth bead. The patients pointed out the intensity of pain on this scale. For the purpose of grading Post-operative analgesia first bead to third bead (25\%). Pain on the scale is taken as no pain to very slight pain and the analgesia is termed as "excellent". Third bead to fifth bead ( $25 \%$ to $50 \%$ ) was termed as mild pain and the analgesia was graded as "good". Fifth bead to seventh bead $(50 \%$ to $70 \%)$ is moderate pain and the analgesia was graded as "fair". Pain of $75 \%$ and above on the scale was taken as severe pain and the analgesia graded as "poor". The point of $75 \%$ pain (seventh bead on the scale) is the point at which postop. Analgesic supplement was given.

Patients were explained the procedure of spinal anesthesia at the time of pre-anesthetic evaluation. After shifting the patient to the operation theatre, intravenous access was secured with $18 \mathrm{G}$ cannula. Under strict aseptic precautions LP was performed using 22/ 25-gauge disposable Quincke type of spinal needle at $\mathrm{L}_{3}-\mathrm{L}_{4}$ spinal intervertebral space by midline approach. The operating table was kept horizontal with no tilt. LP was performed in either lateral decubitus or sitting position.

Patients were monitored continuously using electrocardiography, NIBP and pulse oximetry. In supine position before the spinal injection baseline arterial blood pressure and heart rate was recorded.

Considering duration of analgesia as one of the outcomes, sample size was estimated. Based on the study by Stocks G M ${ }^{3}$ et al, with standard deviation of 19.81 and 25.95 in control and study arm, in order to observe a minimum mean difference of 20 min between the study, with 5\% level of significance and $80 \%$ power after adjusting for multiple comparison, the number of subjects required in each group was 25 , hence totally 75 subjects were recruited.

75 patients were randomly allocated into three following groups by computer generated table.

Group A: SAB with $2.5 \mathrm{ml}$ of $0.5 \%$ Bupivacaine hydrochloride (hyperbaric) alone.
Group B: SAB with addition of $10 \mu$ g fentanyl to $2.5 \mathrm{ml}$ of $0.5 \%$ Bupivacaine hydrochloride (hyperbaric)

Group C: SAB with addition of $25 \mu \mathrm{g}$ fentanyl to $2.5 \mathrm{ml}$ of 0.5\% Bupivacaine hydrochloride (hyperbaric).

\section{Group A}

LP was performed after the free flow of CSF $2.5 \mathrm{ml}$ of $0.5 \%$ Bupivacaine hydrochloride (hyperbaric) was injected intrathecally over 20 seconds with the bevel of spinal needle facing upwards. After SAB patient turned supine and surgery followed as usual.

\section{Group B}

$2.5 \mathrm{ml}$ of $0.5 \%$ Bupivacaine hydrochloride (hyperbaric) was taken in a $5 \mathrm{ml}$ syringe. Fentanyl Citrate $10 \mu \mathrm{g}$ preservative free, was measured in a 40-units (1-ml) insulin-syringe for accuracy in measuring. 8 units $(10 \mu \mathrm{g})$ of Fentanyl Citrate was taken in the insulin syringe from a $2 \mathrm{ml}$ amp of Fentanyl Citrate containing $100 \mu \mathrm{g}(1 \mathrm{ml}=50 \mu \mathrm{g})$. This was added to the $5 \mathrm{ml}$ syringe containing $2.5 \mathrm{ml}$ of $0.5 \%$ Bupivacaine hydrochloride (hyperbaric). LP performed, after free flow of CSF this mixture was injected intrathecally.

\section{Group C}

$2.5 \mathrm{ml}$ of $0.5 \%$ Bupivacaine hydrochloride (hyperbaric) was taken in a $5 \mathrm{ml}$ syringe. 20 units $(25 \mu \mathrm{g})$ of fentanyl citrate was taken in a 40 -units $(1 \mathrm{ml})$ insulin-syringe from a $2 \mathrm{ml}$ amp of Fentanyl Citrate containing $100 \mu \mathrm{g}(1 \mathrm{ml}=50 \mu \mathrm{g})$. This was added to the $5 \mathrm{ml}$ syringe containing $2.5 \mathrm{ml}$ of $0.5 \%$ Bupivacaine hydrochloride (hyperbaric). LP performed, after free flow of CSF this mixture was injected intrathecally. Base line Heart Rate and blood pressure was noted down before SAB. After spinal anaesthesia all the patients were turned supine, pulse rate and blood pressure were recorded immediately and at 5, 10, 15, 30, 60, 120, 180 minutes. Level of sensory blockade was checked with a 23G hypodermic needle immediately after SAB and at 5, 10, 15, 30, 60, 120, 180 minutes.

Level of motor blockade was also assessed by using the ${ }^{\circ}$ Bromage scale immediately after SAB and at 5, 10, 15, 30, 60, 120,180 minutes.

( ${ }^{\circ}$ Bromage scale 0 -full flexion of knees and feet; 1 - just able to flex knees, full flexion of feet; 2-unable to flex knees, but some flexion of feet possible, 3-unable to move legs or feet.) Time for two segment regression of sensory level in minutes was also noted down.

Side effects such as nausea, vomiting, pruritis, shivering, desaturation or hypoxemia (SpO2 < 90\%), respiratory depression ( $R R<10$ breaths per minute)), hypotension, drowsiness, euphoria or dysphoria, chest tightness, urinary retention. Hypotension was defined as decrease in systolic blood pressure more than $30 \%$ of base line and was treated with Inj. Ephedrine $6 \mathrm{mg}$ increments IV. Inj. Atropine was given when heart rate decreases $>=20 \%$ of base line.

The retention of if any urine was noted in the non catheterized patients.

The duration of post- operative analgesia was calculated from the time when the block was given. The patients were followed up for 24 hours after surgery. They were asked to point out the intensity of their pain on the linear visual pain scale. VAS score along with heart rate and blood pressure was 
recorded in the recovery room (3 hours after $S A B$ ), evening of surgery (6 hours after $\mathrm{SAB}$ ) and on the first post-operative day (24 hours after SAB). During the post-operative period the injections of analgesics or opioids were avoided until demanded by the patients due to pain. The time at which supplementation given was noted down along with drug and dosage. This point corresponded to poor analgesia on the scale. Total dose of analgesics administered to the patients in 24 hours was noted. Pain assessment was conducted by a single observer. The time taken for complete motor and sensory recovery was noted. The duration of motor blockade was taken from the time of injection of the drug to the time when the patient was able to move his ankle. The duration of sensory blockade was taken from the time of injection of the drug to the time when the patient was able to appreciate pain in the S1 dermatome (i.e. the heel.)

\section{Statistical Methods}

Statistical analysis results were expressed as mean \pm SD (Standard Deviation). Assumption of normality was assessed. All the clinical parameters were compared between three groups using analysis of variance for normally distributed continuous variables. Multiple comparison was done using Bonferroni correction. Post analgesia haemodynamic parameters were compared between three groups adjusted for baseline measurement using repeated measures analysis of variance (ANOVA). Visual analog scores were compared using nonparametric methods. $\mathrm{P}$ value less than $5 \%$ was considered statistically significant. All the analyses were done using SPSS version 21.0.

\section{RESULTS}

There was no significant difference between the three groups with respect to age, height, weight, systolic, diastolic blood pressures and heart rate at different time intervals (Table 1 $7)$. The time for 2 segment regression of sensory level in group B (119 mins.) and group C (117) was significantly slower than group A (99) ( $p<0.0001)$. The difference between the groups for time to full motor recovery was not significant. Time of first request for post-operative analgesia by the patient was greater in Group C (638 min.) as compared to Group B (556 mins.) and Group A (313 min.) which was statistically significant. Time noted for Group B also was significantly longer than Group A. The total dose of analgesics received by the patient in the first $24 \mathrm{hrs}$. Was significantly higher in Group A (3.56) as compared to Group B (1.96) and Group C (1.80) (Table 8). VAS pain scores were highest in Group A at $3 \mathrm{hrs}, 6 \mathrm{hrs}$ and $24 \mathrm{hrs}$, as compared to Group B and Group C (Table 9). It was statistically significant. Regarding side effects, only one patient had nausea along with vomiting in group $\mathrm{B}$, in group $\mathrm{C}$ one patient had shivering and one patient had pruritis.

\begin{tabular}{|c|c|c|c|c|}
\hline \multirow{2}{*}{ Age } & $\begin{array}{c}\text { Group A } \\
\mathbf{n = 2 5}\end{array}$ & $\begin{array}{c}\text { Group B n = } \\
\mathbf{2 5}\end{array}$ & $\begin{array}{c}\text { Group C n } \\
\mathbf{2 2 5}\end{array}$ & P value \\
\cline { 2 - 5 } & $42.4 \pm 14.4$ & $42.3 \pm 19.0$ & $42.0 \pm 16.2$ & 0.99 \\
\hline Height & $5.70 \pm 0.37$ & $5.67 \pm 0.44$ & $5.42 \pm 0.45$ & 0.28 \\
\hline Weight & $60 \pm 7.92$ & $61 \pm 10.0$ & $61 \pm 11.6$ & 0.88 \\
\hline Table 1. Comparison of Age, Height and Weight by Study \\
Groups \\
\hline
\end{tabular}

Reported as mean \pm SD

\begin{tabular}{|c|c|c|c|c|}
\hline & Group A & Group B & Group C & $\begin{array}{c}\text { P } \\
\text { value }\end{array}$ \\
\hline $\begin{array}{c}\text { Base } \\
\text { Line } \\
0\end{array}$ & $126.80(14.35)$ & $124.88(11.70)$ & $129.08(17.88)$ & 0.61 \\
\hline 5 & $121.20(9.27)$ & $118.92(11.44)$ & $123.56(10.97)$ & 0.31 \\
\hline 10 & $121.92(14.96)$ & $113.44(12.71)$ & $117.44(15.60)$ & 0.12 \\
\hline 15 & $119.80(14.75)$ & $115.56(11.59)$ & $117.88(12.74)$ & 0.52 \\
\hline 30 & $119.52(25.98)$ & $114.36(8.42)$ & $119.76(14.92)$ & 0.06 \\
\hline 60 & $120.96(14.91)$ & $115.60(8.90)$ & $120.52(12.93)$ & 0.25 \\
\hline 120 & $121.16(13.21)$ & $117.40(9.87)$ & $120.24(12.10)$ & 0.51 \\
\hline 180 & $120.80(10.77)$ & $118.64(9.46)$ & $121.88(13.68)$ & 0.60 \\
\hline 240 & $116.80(8.52)$ & $120.00(10.0)$ & $122.24(11.85)$ & 0.17 \\
\hline \multicolumn{5}{|c|}{ Table 2. Shows Systolic Blood Pressure at Different Time } \\
Intervals by Study Groups \\
\hline \multicolumn{5}{|c}{}
\end{tabular}

\begin{tabular}{|c|c|c|c|c|}
\hline $\begin{array}{c}\text { Time in } \\
\text { Minutes }\end{array}$ & Group A & Group B & Group C & P Value \\
\hline Base line 0 & $76.64(7.11)$ & $75.88(8.17)$ & $78.96(8.59)$ & 0.37 \\
\hline 5 & $72.00(5.77)$ & $73.08(9.80)$ & $75.40(9.57)$ & 0.36 \\
\hline 10 & $71.76(5.98)$ & $70.08(6.96)$ & $67.76(9.33)$ & 0.18 \\
\hline 15 & $72.00(6.46)$ & $70.0(7.49)$ & $68.32(7.95)$ & 0.21 \\
\hline 30 & $72.00(5.77)$ & $70.0(7.81)$ & $70.84(7.97)$ & 0.62 \\
\hline 60 & $71.20(6.66)$ & $70.0(6.04)$ & $69.84(7.85)$ & 0.75 \\
\hline 120 & $71.88(5.85)$ & $70.96(6.76)$ & $71.84(7.51)$ & 0.86 \\
\hline 180 & $71.60(4.73)$ & $71.60(4.73)$ & $70.64(5.50)$ & 0.74 \\
\hline 240 & $71.60(4.73)$ & $70.0(5.78)$ & $71.60(4.73$ & 0.44 \\
\hline Table 3. Shows Diastolic Blood Pressure at Different Time \\
Intervals by Study Groups \\
\hline
\end{tabular}

\begin{tabular}{|c|c|c|c|c|}
\hline & Group A & Group B & Group C & P value \\
\hline $\begin{array}{c}\text { Base } \\
\text { Line 0 }\end{array}$ & $88.72(12.81)$ & $82.64(12.21)$ & $92.64(11.43)$ & 0.01 \\
\hline 5 & $88.68(11.77)$ & $84.80(11.77)$ & $92.84(15.28)$ & 0.11 \\
\hline 10 & $87.44(11.32)$ & $82.96(13.34)$ & $91.84(15.38)$ & 0.07 \\
\hline 15 & $85.24(9.80)$ & $83.36(13.65)$ & $88.84(14.99)$ & 0.32 \\
\hline 30 & $82.00(9.62)$ & $79.32(13.84)$ & $87.12(15.10)$ & 0.11 \\
\hline 60 & $80.44(8.87)$ & $77.80(14.95)$ & $84.60(14.25)$ & 0.18 \\
\hline 120 & $80.28(8.13)$ & $77.76(14.20)$ & $84.12(13.12)$ & 0.18 \\
\hline 180 & $79.44(7.82)$ & $77.28(13.60)$ & $84.68(14.30)$ & 0.09 \\
\hline 240 & $78.64(8.70)$ & $77.40(13.65)$ & $86.08(14.23)$ & $<0.05$ \\
\hline Table 4. Showing Heart Rate Recording at Different Time \\
Intervals by Study Groups \\
\hline \multicolumn{5}{|c|}{} \\
\hline
\end{tabular}

\begin{tabular}{|c|c|c|c|c|}
\hline & Group A & Group B & Group C & P value \\
\hline $\begin{array}{c}\text { After } 3 \\
\text { hours }\end{array}$ & $120.8(10.77)$ & $117.84(9.31)$ & $121.60(13.86)$ & 0.47 \\
\hline $\begin{array}{c}\text { After 6 } \\
\text { hours }\end{array}$ & $123.6(8.60)$ & $120.0(10.0)$ & $122.8(10.61)$ & 0.39 \\
\hline $\begin{array}{c}\text { After 24 } \\
\text { hours }\end{array}$ & $123.6(9.52)$ & $119.6(8.89)$ & $124.32(9.99)$ & 0.17 \\
\hline Table 5. Showing Systolic Blood Pressure at 3 hrs., 6 hrs., \\
and 24 hrs. \\
\hline
\end{tabular}

\begin{tabular}{|c|c|c|c|c|}
\hline & Group A & Group B & Group C & P value \\
\hline After 3 hrs & $71.2(4.40)$ & $70.8(4.93)$ & $71.6(5.54)$ & 0.85 \\
\hline $6 \mathrm{hrs}$ & $71.2(4.40)$ & $70.8(4.0)$ & $71.2(3.17)$ & 0.92 \\
\hline 24 hrs & $71 .(4.40)$ & $69.6(2.0)$ & $72(4.36)$ & $<0.05$ \\
\hline Table 6. Showing Diastolic Blood Pressure at 3 hrs., 6 hrs., \\
and 24 hrs. \\
\hline
\end{tabular}




\begin{tabular}{|c|c|c|c|c|}
\hline Heart Rate & Group A & Group B & Group C & P value \\
\cline { 1 - 4 } After 3 & $80.8(8.79)$ & 77.44 & 84.68 & \\
hours & $(13.41)$ & $(14.48)$ & 0.13 \\
\cline { 1 - 4 } After 6 & $80.8(8.73)$ & 78.08 & 84.72 & 0.11 \\
hours & $(12.64)$ & $(12.26)$ & 0.13 \\
\cline { 1 - 3 } After 24 & $80.0(9.04)$ & 79.36 & 85.24 & \\
hours & $(11.83)$ & $(11.96)$ & \\
\hline Table 7. Shows Changes in Heart Rate at 3 hours, 6 hours \\
and 24 hours \\
\hline
\end{tabular}

\begin{tabular}{|c|c|c|c|c|}
\hline & $\begin{array}{c}\text { Group } \\
\text { A }\end{array}$ & $\begin{array}{c}\text { Group } \\
\text { B }\end{array}$ & $\begin{array}{c}\text { Group } \\
\text { C }\end{array}$ & $\begin{array}{c}\text { P } \\
\text { value }\end{array}$ \\
\hline $\begin{array}{c}\text { Time for 2 segment } \\
\text { regression of sensory } \\
\text { level }\end{array}$ & $\begin{array}{c}99 \pm \\
20.1^{*}\end{array}$ & $\begin{array}{c}119.2 \pm \\
16.2\end{array}$ & $\begin{array}{c}117.6 \pm \\
17.9\end{array}$ & $<0.0001$ \\
\hline $\begin{array}{c}\text { time to full motor } \\
\text { recovery }\end{array}$ & $\begin{array}{c}202.8 \pm \\
19.3\end{array}$ & $\begin{array}{c}202.6 \pm \\
10.5\end{array}$ & $\begin{array}{c}200.8 \pm \\
14.6\end{array}$ & 0.88 \\
\hline $\begin{array}{c}\text { Time to complete } \\
\text { motor sensory } \\
\text { recovery }\end{array}$ & $\begin{array}{c}201.2 \pm \\
16.3\end{array}$ & $\begin{array}{c}202.6 \pm \\
10.1\end{array}$ & $\begin{array}{c}210.6 \pm \\
14.2\end{array}$ & 0.93 \\
\hline $\begin{array}{c}\text { Time of first request } \\
\text { for analgesia }\end{array}$ & $\begin{array}{c}313.2 \pm \\
157.9\end{array}$ & $\begin{array}{c}556.8 \pm \\
179.6^{*}\end{array}$ & $\begin{array}{c}638.8 \pm \\
313.1^{*}\end{array}$ & $<0.001$ \\
\hline $\begin{array}{c}\text { Total dose of } \\
\text { analgesics }\end{array}$ & $\begin{array}{c}3.56 \pm \\
1.12^{*}\end{array}$ & $\begin{array}{c}1.96 \pm \\
0.68\end{array}$ & $\begin{array}{c}1.80 \pm \\
0.58\end{array}$ & $<0.001$ \\
\hline $\begin{array}{c}\text { Table 8. Comparison of Time and Dose Outcomes between } \\
\text { the Three Study Groups }\end{array}$ \\
\hline
\end{tabular}

${ }^{*}$ Group A is significantly different from group B and C using Bonferroni Correction post hoc analysis;

\begin{tabular}{|c|c|c|c|c|}
\hline & Group A & Group B & Group C & P value \\
\hline $3 \mathrm{hrs}$ & $0.68(1.70)$ & 0.00 & $0.04(0.20)$ & $<0.005$ \\
\hline $6 \mathrm{hrs}$ & $3.80(0.96)$ & $0.84(0.37)$ & $1.12(0.53)$ & $<0.001$ \\
\hline $24 \mathrm{hrs}$ & $4.52(1.16)$ & $0.96(0.54)$ & $1.52(0.65)$ & $<0.001$ \\
\hline Table 9. Shows VAS Pain Scores at 3 hrs., 6 hrs. and at 24 \\
hrs. \\
\hline
\end{tabular}

\section{DISCUSSION}

Subarachnoid block was once the commonest local anaesthetic technique and would probably maintain its place in the developing countries because of simplicity, minimal skill requirement, rapidity of onset, economy and minimal postoperative complications. The drugs used for spinal subarachnoid block are lignocaine, \& bupivacaine. One disadvantage with spinal anaesthesia using LA alone is that analgesia ends with the regression of the block. Which means that there is early postoperative need for analgesia.

Post-operative pain is one of the most frequent adverse effects occurring after surgery. Optimum pain management is the corner stone of the efficiency of surgical care. The use of neuraxial opioids has improved the quality of intra operative analgesia produced by the local anaesthetic by binding directly with spinal opiate receptor and prolonging the duration of postoperative analgesia. Animal studies have also demonstrated antinociceptive synergism between intrathecal opioid and local anaesthetics during visceral and somatic nociception.

Fentanyl (A lipophilic opioid), has a rapid onset and a shorter duration of action following intrathecal administration but its duration of action is dose dependent. It prolongs the duration of Bupivacaine induced sensory blockade. This suggests a potential synergism between fentanyl and Bupivacaine as reported in an animal study by Wang et al. ${ }^{4}$ This method of administration offers patients significant benefits over traditional intermittent opioid administration where PCA facilities are not available.

Gielen MJM ${ }^{5}$ et al in 1993 reported that fentanyl is one of the safest opioids. Animal studies by Gissen AJ et al ${ }^{6}$ in 1987 have demonstrated the safety of fentanyl with regard to neurotoxicity. None of the neurological complications experienced.

In the present study all the patients were monitored clinically in the intraoperative period. Pulse rate, systolic blood pressure and respiratory rate were noted at regular intervals. In the present study none of the patient in the 3 groups had a fall in systolic blood pressure ( $>30 \%$ of basal). That means blood pressure in all the three groups was comparable and statistically not different. Hunt C.O. et $\mathrm{al}^{7}$ in 1987, Belzerina et al8 in1992, Harbhej Singh et al9 in1995 with different doses of drug used found no significant changes in their haemodynamics. From the above discussion it seems that intrathecal fentanyl with hyperbaric Bupivacaine does not affect the systolic blood pressure.

None of the patients in our study experienced respiratory depression (RR< 10 breaths/ min) Varrasi G et al ${ }^{10}$ in 1992 studied the ventilatory effect of different dosages of intrathecal fentanyl on elderly patients and concluded that the patients who received 50 mcg fentanyl had respiratory depression and recommended $25 \mathrm{mcg}$ as the only dose without respiratory depression. Reuben SS et al11 in 1994, studied different dosages from 0 to 50 mcg fentanyl and observed that not a single patient had respiratory depression.

In our study in all the three groups we did not find any delay in full motor recovery. Liu S. et al ${ }^{12}$ in 1995 and Ben David B et al ${ }^{13}$ in 1997 found that addition of fentanyl to $0.5 \%$ Bupivacaine does not affect onset, quality and duration of motor blockade.

We found that the time for two segment regression was prolonged in both the fentanyl groups. Liu S. et al12 in 1995 and Harbhej Singh et $\mathrm{al}^{9}$ in 1995 found in their studies that intrathecal fentanyl intensifies and increases duration of sensory anesthesia without prolonging recovery. Chakrabarthi et al ${ }^{14}$ in 2015 also concluded in their study intrathecal fentanyl prolongs duration sensory block with post op analgesia, In the present study, mean duration of analgesia that is time of first request of analgesia in Group A in was 313 mins., in Group B 556 mins and in Group C 638 mins. This was statistically highly significant.

The total dose of analgesics required in 24 hours was highest in group A (mean- 356), when compared to Group B (mean-196) and in Group C (mean-180).

The above results were statistically significant. Harbhej Singh et $\mathrm{al}^{9}$ in 1995 found that intrathecal with $0.5 \%$ fentanyl $25 \mathrm{mcg}$ reduced analgesic requirements in the early postoperative period. Hunt C 0 et al7 in 1987 and Varrassi et al 10 in 1992 found in their studies that intrathecal fentanyl increases the mean duration of analgesia. Thus, the addition of fentanyl to hyperbaric Bupivacaine for spinal anesthesia prolongs the mean duration of analgesia and improves intraoperative as well as immediate postoperative analgesia with no adverse effects.

\section{CONCLUSION}

The addition of intrathecal fentanyl to the local anaesthetic injected intrathecally in sub-arachnoid block prolongs the sensory analgesia obtained by the block without hampering 
recovery from motor block or causing untoward haemodynamic disturbances. Dose of $10 \mu \mathrm{g}$ fentanyl provided all these benefits which were accentuated by increasing the dose to $25 \mu \mathrm{g}$. Hence a dose of $10 \mu \mathrm{g}$ to $25 \mu \mathrm{g}$ as deemed fit is useful for this purpose.

\section{REFERENCES}

[1] Bogra J, Arora N, Srivastava P, et al. Synergistic effect of intrathecal fentanyl and bupivacaine in spinal anesthesia for cesarean section. BMC Anesthesiology 2005;5(1):5.

[2] Mehta S, Dalwadi H, Shah T, et al. Comparative study of low dose bupivacaine-fentanyl Vs. conventional dose of bupivacaine in spinal anaesthesia for orthopedic procedures in elderly patients. Gujarat Medical Journal 2015;70(1):25-8.

[3] Wang C, Koutsoukou-Dritsopoulou A, Chakrabarti MK, et al. Differential effect of alfentanil, fentanyl, pethidine and lignocaine administered intrathecally on nociceptive responses evoked by low and high frequency stimulation of somatic nerves. British Journal of Anesthesia 1993;70(1):63-9.

[4] Stocks GM, Hallworth SP, Fernando R, et al. Minimum local analgesic dose of intrathecal bupivacaine in labor and the effect of intrathecal fentanyl. Anaesthesiology 2001;94(4):593-8.

[5] Gielen MJM. Spinal anesthesia. Current Opinion in Anesthesiology 1993;6(5):803-7.

[6] Gissen AJ, Gugino LD, Datta S, et al. Effects of fentanyl and sufentanil on peripheral mammalian nerves. Anaesthesia Analgesia 1987;66(12):1272-6.
[7] Hunt Co, Datta S, Hauch M, et al. Perioperative analgesia with subarachnoid fentanyl with bupivacaine. Anesthesiology 1987;(67):no. 3A.

[8] Belzarena SD. Clinical effects of intrathecally administered fentanyl in patients undergoing cesarean section. Anesthesia \& Analgesia 1992;74(5):653-7.

[9] Singh H, Yang J, Thornton K, et al. Intrathecal fentanyl prolongs sensory bupivacaine spinal block. Canadian Journal of Anesthesia 1995;42(11):987-91.

[10] Varrassi G, Celleno D, Capongna G, et al. Ventilatory effect of subarachnoid fentanyl in elderly. Anesthesia 1992;47(7):558-62.

[11] Reuben SS, Dunn SM, Duprat KM, et al. An intrathecal fentanyl dose-response study in lower extremity revascularization procedures. Anesthesiology 1994;81(6):1371-5.

[12] Liu S, Chiu AA, Carpenter RL, et al. Fentanyl prolongs lidocaine spinal anesthesia without prolonging recovery. Anesthesia \& Analgesia 1995;80(4):730-4.

[13] Ben-David B, Solomon E, Levin H, et al. Intrathecal fentanyl with small-dose dilute bupivacaine: better anesthesia without prolonging recovery. Anesthesia \& Analgesia 1997;85(3):560-5.

[14] Chakrabarti A, Debroy D, Ray J, et al. The study of haemodynamics and neonatal outcome following spinal anesthesia with low dose hyperbaric bupivacaine with and without fentanyl in patients undergoing elective caesarean. Journal of Research in Anaesthesiology and Pain Medicine 2015;1(1). 